\title{
Engineering Student Leaders' Self-Assessments of Leadership Skills
}

\author{
Robyn Paul and Dr. Lynne Cowe Falls \\ Schulich School of Engineering, University of Calgary \\ rmpaul@ucalgary.ca
}

\begin{abstract}
In the $21^{\text {st }}$ century, graduating engineering students are required to have many skills beyond traditional technical skills. Leadership education in engineering has had an increased development over the past few decades, however there is still a lack of understanding of the effectiveness of these programs. This paper summarizes the results from a pilot study conducted with a group of undergraduate students. Engineering student leaders were given a leadership self-assessment at the beginning and end of their semester. Overall, a slight improvement was observed in the majority of the leadership competencies including character, teamwork, and technical. Male students had a decrease in their teamwork skills. Both genders ranked themselves lowest in technical abilities, however male students rated themselves significantly higher relative to female students. The findings from this study could be useful to develop and improve engineering leadership education programs based on the gaps of student competencies.
\end{abstract}

Keywords: Engineering Leadership, Student SelfAssessment, Student Associations

\section{INTRODUCTION}

The graduate attributes mandated by Canadian Engineering Accreditation Board outline the technical and nontechnical skillset that engineers graduating from Canadian universities should possess. The sixth graduate attribute specifically states that engineers should be able to work in the capacity of a leader within a team setting. The importance of leadership in the engineering workplace has been observed for many years including decades ago when Bernard Gordon [9] made a keynote speech on how leadership is an essential aspect of an engineer's skills. More recently, there has been a growth of interest in the field including the updated CDIO Syllabus [6], and a statement by the National Academy of Engineering [12].
Involvement in student associations has been shown to have a substantial impact on students' leadership development, improving interpersonal abilities, management skills, and self-confidence [2]. As such, in 2007 the Schulich School of Engineering launched the Maier Student Leadership Program. The goal of the program is to accelerate the careers of engineering graduates by providing those who have demonstrated an interest in leadership with guidance and coaching [5]. The program is target to students who have already demonstrated an interested in being involved in student clubs, teams and associations (see [5] for more details). The question then follows, does participation in leadership activities along with program support improve the leadership skills of engineering students?

Answering this question is an ongoing research project and the data presented in this paper is based on a small pilot study sample size. Surveys were distributed to undergraduate engineering students attending the two annual Maier Student Leadership conferences (at the beginning of the year and at the end of the year). The surveys asked the students to rate themselves on a variety of engineering leadership skills.

Results showed both improvements and declines across the different skill areas. The areas of skill improvement show increased student confidence in those skills. The of skill decline could be interpreted as a gained awareness of the complexity of the skill, a reduced confidence in the skill based on negative experience, or other factors as will be discussed in this paper.

\section{ENGINEERING LEADERSHIP}

\subsection{Engineering Leadership Education}

With the growing interest of producing engineering graduates with skills in leadership, engineering leadership education programs have increased over the last few decades. Two summaries, one from 2009 [10] and another in 2012 [11], provide insight into the engineering leadership education practices in North America, Europe and Australia. 
These summaries were able to identify many of the main components of engineering leadership education. However, the three challenges that engineering leadership programs continue to face are (1) a clear definition of engineering leadership; (2) reliable assessment tools; and (3) training programs for faculty members [1]. These challenges are not unreasonable, as leadership itself is has been studied by thousands for hundreds of years, yet it still one of the least understood concepts [8]. This paper looks specifically at the second challenge, using an assessment instrument to measure engineering leadership skill development in undergraduate students.

\section{METHOD}

\subsection{Context: Student Leadership Conferences}

Surveys were distribute at two annual Maier Student Leadership Program conferences at the Schulich School of Engineering. The first conference occurred near the beginning of the school year and will be referred to as the "Fall 2014 Conference" (F14). The second conference occurred near the end of the school year during the second semester and will be referred to as "Winter 2015 Conference" (W15). There was approximately seven months between the two conferences.

The objective of the F14 conference was to set the students up for success. The audience was mostly students who were interested in leadership, or had some leadership experience. The conference provided an opportunity for these students to learn how to be an effective leader in engineering.

The objective of the W15 conference was to reflect on the activities from the past year, to plan for the upcoming year, and to provide guidance on succession procedures for the new incoming leaders. During the W15 conference, the audience was mostly students who had been in leadership positions throughout that school year.

\subsection{Participants}

Participation in the survey was optional, and the details of the participants can be seen below in Table 1 . For the F14 survey, the response rate was approximately $56 \%$ (28 of 50 attendees) and for the W15 survey, the response rate was approximately $74 \%$ (26 of 35 attendees).

\subsection{Survey Content}

The survey given to the students included a selfassessment of their own leadership abilities. This involved a skills questionnaire developed based on the survey instrument created by Ahn et al. [1]. Ahn et al.'s survey contained 45 items specifically designed to measure outcomes in engineering undergraduate students related to leadership, adaptability to change, and synthesis abilities. Twenty of these items, principally the ones directly related to leadership, were chosen for the skills questionnaire (e.g. I independently initiate new individual or team projects). The participants were asked to rank the extent to which they embody each statement on a 4-point Likert scale.

Table 1: Summary of participant demographics.

\begin{tabular}{|c|c|c|c|c|c|}
\cline { 3 - 6 } \multicolumn{2}{c|}{} & \multicolumn{2}{c|}{$\begin{array}{c}\text { Gall 2014 } \\
(\mathbf{n = 3 7})\end{array}$} & \multicolumn{2}{c|}{$\begin{array}{c}\text { Winter 2015 } \\
(\mathbf{n = 2 6})\end{array}$} \\
\cline { 3 - 6 } \multicolumn{2}{c|}{} & $\mathrm{n}$ & $\%$ & $\mathrm{n}$ & $\%$ \\
\hline \multirow{3}{*}{$\begin{array}{c}\text { Year of } \\
\text { Study }\end{array}$} & $1^{\text {st }}$ & 4 & $11 \%$ & 0 & $0 \%$ \\
\cline { 2 - 6 } & $2^{\text {nd }}$ & 7 & $19 \%$ & 10 & $39 \%$ \\
\cline { 2 - 6 } & $3^{\text {rd }}$ & 15 & $41 \%$ & 8 & $31 \%$ \\
\cline { 2 - 6 } & $4^{\text {th }}+$ & 10 & $27 \%$ & 8 & $31 \%$ \\
\hline \multirow{2}{*}{ Gender } & $\mathrm{F}$ & 23 & $62 \%$ & 14 & $54 \%$ \\
\cline { 2 - 6 } & $\mathrm{M}$ & 14 & $38 \%$ & 12 & $46 \%$ \\
\hline $\begin{array}{c}\text { Previous } \\
\text { attendee? }\end{array}$ & Yes & 13 & $35 \%$ & 17 & $65 \%$ \\
\cline { 2 - 6 } & No & 24 & $65 \%$ & 9 & $35 \%$ \\
\hline
\end{tabular}

\subsection{Data Analysis}

The data from the self-assessment was analyzed by determining the average rating and standard deviation for each of the twenty question. It is worthwhile to note that two questions included were phrased in the negative (e.g. I hesitate to make crucial decisions on project-related issues). The complement was thus determined for the analysis of these two questions.

Each of the questions were grouped into three categories in order to compare the data across similar types of skills. These three categories of skills were character, teamwork, and technical abilities.

\section{RESULTS AND DISCUSSION}

\subsection{Overall Results}

The question with the lowest average rating of 2.57 was I hesitate to make crucial decisions on projectrelated issues. The highest rated question had a rating of 3.67 and was I listen to my peers' concerns and opinions even if they are different from my own. The standard deviations across all questions ranged from 0.48 to 0.92 .

The questions were grouped into the three categories and the result was seven "Character" questions, eight "Teamwork" questions, and five "Technical" questions. A comparison of these three categories can be seen in Fig. 1.

It is notable that both in F14 and W15 the technical skills were rated the lowest and the teamwork skills were rated the highest. Research of engineering leadership programs has indicated that the majority of the programs 
are taught outside the context of engineering [10]. As the Maier Student Leadership Program is an extracurricular program for students, it is no different. The lack of integration within the technical curriculum could be an explanation for the weaker technical skills. One of the standards within the CDIO Syllabus emphasizes the importance of integrating interpersonal skills into the engineering curriculum so that students are able to apply the knowledge to their future technical career [6].

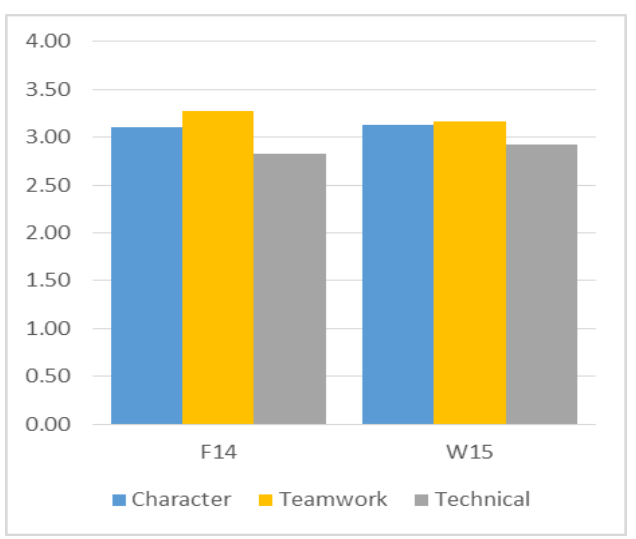

Fig. 1. Results from the F14 and W15 surveys within the three categories of questions.

\subsection{Female and Male Individual Analysis}

Analysis of the responses from the female participants is shown in Fig. 2. Very little difference was observed from the beginning of term (F14) to the end of term (W15), however there was a slight increase for each of the three categories.

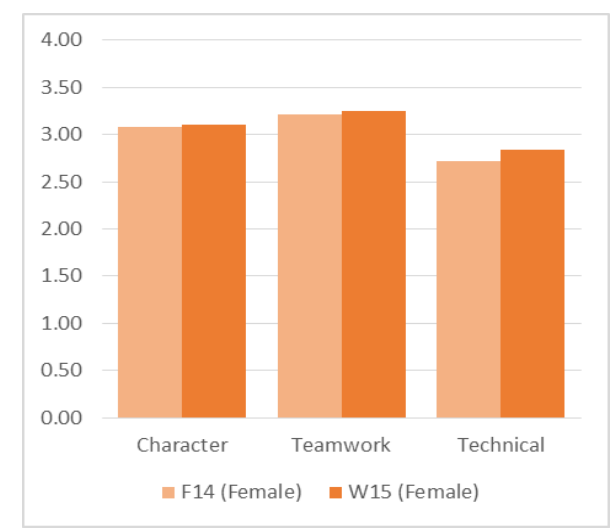

Fig. 2. Female results compared from F14 to W15 within the three categories of questions.

The same data is shown for the male participants in Fig. 3. The male students had a slight increase in the categories of "Character" and "Technical," similar to the female students. However the "Teamwork" category had a relatively large decrease.

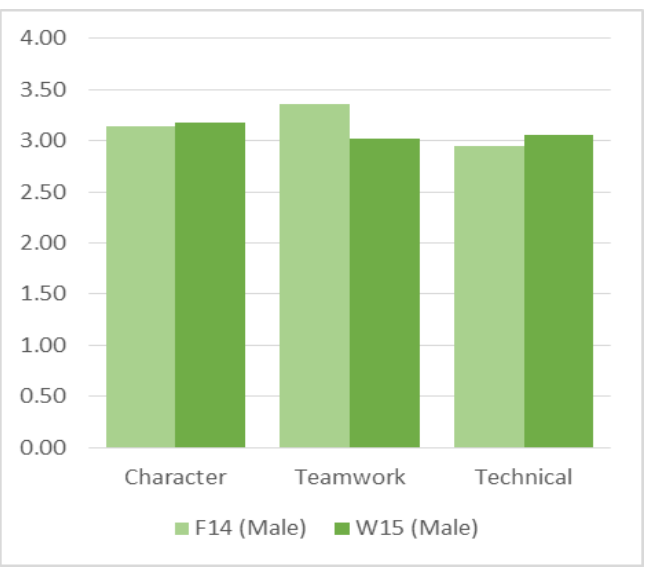

Fig. 3. Male results compared from F14 to W15 within the three categories of questions.

Male students have been shown to rate their team dynamic abilities more positively than female students [13]. Prior to significant leadership experience the male students may have rated themselves more generously in their teamwork abilities. However, after experience and realization of the difficulty of teamwork, they rated themselves lower at the end of the term.

Another explanation for the decrease in teamwork skills could be due to challenging team experiences that reduced the confidence of the male students' abilities. Lastly, due to the small sample size for this pilot study, the variation could be explained by the standard deviation.

\subsection{Female and Male Comparison}

Next, the results for female and male students were compared to each other. Figure 4 shows the comparison from the F14 data, and Fig. 5 for the W15 data.

In F14, the male students rated themselves higher in all three of the categories. The largest difference was seen in the technical skills. Research shows that male students tend to have higher confidence in their technical abilities, [14]. Female students are often not only less confident in their technical abilities, but they also have less confidence in their ability to apply their knowledge to a career in the industry [15]. The issue of female confidence is important to address as it is believed to be one of the contributing factors to the gender gap in engineering, a gap that is even more prominent when looking at engineering leaders [7].

In W15, the categories "Character" and "Technical" were similar to the F14 results, however the male students rated themselves lower than the female students in "Teamwork." The male's reduced teamwork confidence was discussed previously based on Fig. 3. Since the female students did not reduce their self-assessment of teamwork skills, it is likely the male students overestimated their rating at the beginning of term prior to having significant leadership and teamwork experience. 


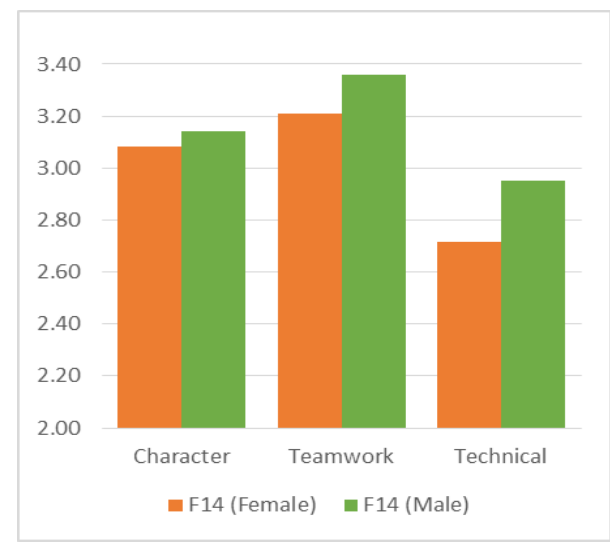

Fig. 4. Fall 2014 Conference, comparing gender results within the three categories of questions.

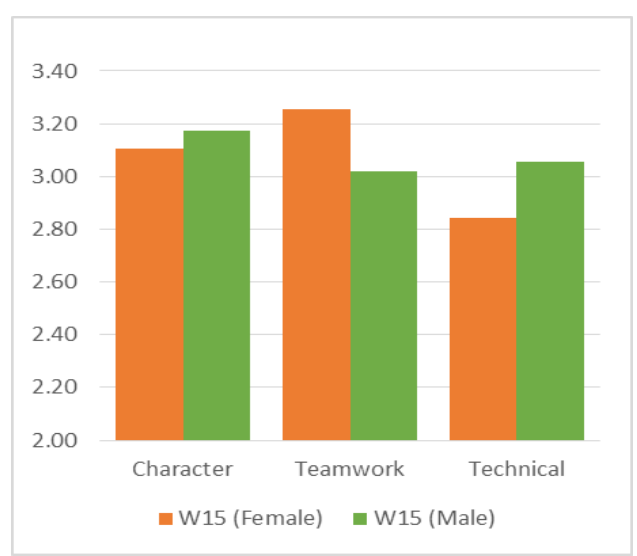

Fig. 5. Winter 2015 Conference, comparing gender results within the three categories of questions.

Overall, the observations form this pilot students and the differences discussed above are relatively small based on the standard deviations observed.

When analyzing the results from the individual questions, the one question that had the most significant results with the highest difference was I perceive myself to be technically competent. In F14, males rated themselves 0.75 higher than females, and in W15 they rates themselves 0.85 higher than females. Again, this emphasizes the need to encourage female students to view themselves as technically competent individuals.

Although male students often do rate themselves higher in areas such as assertiveness and intelligence, female students rate themselves higher on being open to new experiences, helpful and hardworking [3]. These areas of confidence in female students could be used to increase their technical confidence. Service-learning has been shown to be a useful learning tool for learning technical skills, particularly for female students [4].
However, the findings from this could be useful to develop and improve engineering leadership education programs based on the gaps of student competencies.

\section{CONCLUSIONS}

After a year of leadership experience and mentorship from the Maier Student Leadership Program, a slight increase in students' leadership skills was observed, however further data is required to validate these results. The study's findings can be used to improve engineering leadership programs in order to address the gaps being observed in students' skills.

From the survey, it is evident that engineering student have the lowest confidence in their technical abilities as leaders. Female student leaders had a particularly low confidence in their technical abilities. Integration of engineering leadership education within the content of the curriculum would be an important step to improve students' technical confidence.

Future studies will collect further data, comparing the results from students who participated in leadership activities to those who did not. An increased number of participations will also allow for the data to be broken down for analysis of different demographic groups, including year of study and ethnic background.

\section{References}

[1] Benjamin Ahn, Monica F. Cox, Jeremi London, Osman Cekic, and Jiabin Zhu, "Creating an instrument to measure leadership, change, and synthesis in engineering undergraduates," Journal of Engineering Education, vol. 103, no. 1, pp. 115-136, 2014. Available online as of April 30, 2015 from http://onlinelibrary.wiley.com/ doi/10.1002/ jee.20036/abstract

[2] Mozhgan Amirianzadeh, Parivash Jaafair, Nadergholi Ghourchian, and Bahram Jowkar, "Role of Student Associations in Leadership Development of Engineering Students," Proc. $2^{\text {nd }}$ World Conference on Psychology, Counselling and Guidance 2011, Demet Erol Ongen, Cigdem Hursen, Melahat Halat, and Hayat Boz (ed.), (Turkey; 25-30 May 2011), pp. 382-385. Available as of April 30, 2015 from http://dx.doi.org/10.1016/j.sbspro.2011.10.075

[3] Kevin C. Bosner, "Gender Stereotypes and SelfPerceptions among College Students," Journal of Diversity Management, vol. 3, no., 3, pp.41-52, 2008. Available online as of April 30, 2015 from http:// cluteinstitute.com/ojs/index.php/JDM/article/view/4995

[4] Adam Robert Carberry, "Characterizing learning-throughservice students in engineering by gender and academic year," Ph.D. dissertation, Department of Math, Science, Technology, and Engineering Education, Tufts University, Medford, MA, 2010 
[5] Lynne Cowe Falls, Robyn Paul, and Gord Aker, "Developing a New Generation of Leadership at the University of Calgary: Case Study on the Maier Student Leadership Program," in Proc.122nd American Society for Engineering Education Annual Conference, (Seattle, WA; 14-17 June 2015).

[6] Edward F. Crawley, Johan Malmqvist, Sören Östlund, Doris R. Brodeur, and Kristina Edstrom, Rethinking Engineering Education, Second. Dordrecht, Switzerland: Springer, 2014. \{ISBN: 978-3-319-05560-2\}

[7] John P. Dugan, Kimberly Q. Fath, Shannon D. Howes, Kathryn R. Lavelle, and Joshua R. Polanin, "Devloping the leadership capacity and leader efficacy of college women in science, technology, engineering, and math fields," Journal of Leadership Studies, vol. 7, no. 3, pp. 623, 2013. Available as of April 30, 2015 from http://dx.doi.org/10.1002/jls.21292

[8] Sham Sul Kamal Wan Fakeh, Mohd Sazili Shahibi, Adnan Jamaludin, Mohd Rukhaire Rahim, Jailani Paiman, and Zaharudin Ibrahim, "Understanding Leadership Values Among Under Graduate Students in UITM: Their Values, Beliefs, and Motivation," International Journal of Innovative Research in Computer Science and Technology, vol. 2, no. 3, pp. 1-6, 2014. Available as of April 30, 2015 from

www.ijircst.org/User/Arch.aspx?rep=16

[9] Bernard M. Gordon, What is an engineer? Keynote Address at the. European Society for Engineering Education Annual Conference (Erlandgen, Germany; 1984).

[10] Ruth Graham, Edward Crawley, Bruce R. Mendelsohn, “A snapshot review of international good practice: White Paper," sponsored by the Bernard M. Gordon-MIT Engineering Leadership Program, 2009.
[11] Hamid Khattak, Harry Ku, and Steven Goh, "Courses for teaching leadership capacity in professional engineering degrees in Australia and Europe," European Journal of Engineering Education, vol. 37, no. 3, pp. 279-296, Jun. 2012. Available as of April 30, 2015 from http://dx.doi.org/10.1080/03043797.2012.684671

[12] National Academy of Engineering, "The Engineer of 2020: Visions of Engineering in the New Century," 2005. Available as of April 30, 2015 from http://www.nap.edu/catalog/10999.html \{ISBN: 0-309-53065-2\}

[13] Hejung Ro and Youngsoo Choi, "Student Team Project: Gender Differences in Team Project Experience and Attitudes Toward Team-Based Work," Journal of Teaching in Travel \& Tourism, vol.11, pp. 149-163, 2011. Available as of April 30, 2015 from http://www.tandfonline.com/doi/abs/10.1080/ 15313220.2011 .575022

[14] John A. Ross, Catherine D. Bruce, and Garth Scott, "The Gender Confidence Gap in Fractions Knowledge: Gender Differences in Student Belief-Achievement Relationships," School Science and Mathematics, vol. 11, no. 5, pp. 278-288, 2012. Available as of April 15, 2015 from http://dx.doi.org/10.1111/j.1949-8594.2012.00144.x

[15] Haifa Takruri-Rizk, Katherine Jensen, and Kathryn Booth, "Gendered Learning Experience of Engineering and Technology Students," SIGCAS Computers and Society, vol. 38, no. 1, pp. 40-52, 2008. Available as of April 30, 2015 from http://dx.doi.org/10.1145/1361255.1361257 